\section{Las defunciones de carácter ocupacional y la globalización económica}

Aunque las defunciones por causas de origen laboral representan un problema de gran magnitud en el mundo entero, suelen recibir muy poca atención. Según datos recientes de la Organización Internacional del Trabajo (OIT), 1,1 millones de personas mueren en el mundo cada año como consecuencia de trastornos de origen ocupacional, muchas más que las que mueren en accidentes automovilísticos (999 000) y conflictos bélicos (502 000).

Las defunciones de origen laboral se pueden dividir en dos grandes categorías: 1) las provocadas por accidentes en el lugar de trabajo (accidentes de tránsito, accidentes con maquinarias, homicidios, caídas, electrocuciones, etc.), y 2) las ocasionadas por enfermedades ocupacionales que, en Estados Unidos, tienen una frecuencia casi 10 veces mayor que las primeras. No obstante, no hay datos fidedignos ni registros destinados a las defunciones por estas enfermedades. El consecuente subregistro se observa especialmente en el caso de la leucemia en trabajadores expuestos al benceno; el cáncer de vejiga urinaria por exposición a algunas tinturas; el cáncer de pulmón y de otros órganos por exposición al asbestos, y el cáncer de senos paranasales en trabajadores expuestos al aserrín. El asma de tipo alérgico, las enfermedades cardiovasculares por estrés y por exposición a determinadas toxinas, y diversas enfermedades infecciosas producidas por contagio en trabajadores de la salud son otros ejemplos de afecciones subregistradas de carácter ocupacional.

Según un estudio epidemiológico efectuado por investigadores estadounidenses, hay datos de la OIT que revelan que los países escandinavos tienen las menores tasas de muertes de origen ocupacional, desde 2,1 por 100000 habitantes en Suecia hasta 3,2 en Finlandia; en la Unión Europea, la tasa es de 5,9; en Estados Unidos, 5,3; en Canadá, 6,9. Finalmente, los países en desarrollo tienen las tasas más altas: en América Latina y el Caribe, 13,5; en Tailandia, 19,2 y en la República de Korea, 34 .

En teoría, la globalización de la economía puede mejorar las condiciones de trabajo en el mundo entero y, por ende, reducir las defunciones de origen laboral. Hasta ahora no hay indicios, sin embargo, de que esto esté ocurriendo, quizá porque cada día surgen industrias improvisadas que contratan a personas sin experiencia en el sector indus- trial. Otro resultado de la globalización es la llamada "exportación de riesgos" debido al traslado de industrias a países en desarrollo donde no rigen los mismos estándares estrictos de seguridad. Esto, en cierta medida, también ejerce una presión sobre los países industrializados que los lleva a bajar sus estándares.

En países avanzados surgen, además, otras inquietudes. La fuerza de trabajo se compone cada vez más de personas mayores y de distintas razas y nacionalidades que pueden ser más susceptibles a sufrir accidentes y enfermedades de origen laboral. Todos estos datos apuntan a la necesidad de imponer medidas para que se observen los reglamentos de seguridad en los lugares de trabajo y de dar prioridad a la recolección de datos sobre enfermedades y accidentes laborales y al desarrollo de metodologías para identificar y cuantificar los riesgos a los que están expuestos los inmigrantes y otros grupos vulnerables. (Robin $\mathrm{H}$, Landrigan PJ. Work-related death: a continuing epidemic. Am J Public Health 2000;90:541-545.)

\section{Las neoplasias intracervicales en mujeres positivas a VIH y al virus del papiloma humano}

La relación causal entre el virus del papiloma humano (VPH) y el cáncer de cuello uterino está ampliamente establecida, pero aún no se sabe por qué solamente algunas de las mujeres infectadas por el virus llegan a padecer lesiones precancerosas o cáncer invasor. Con la aparición del virus de la inmunodeficiencia humana (VIH), se detectó un riesgo aumentado de neoplasias intracervicales (NIC) en mujeres inmunodeprimidas por el VIH e infectadas por el VPH. Además, se observó que las mujeres con seropositividad a VIH tenían una mayor prevalencia de infección por VPH. Se ha especulado que la inmunosupresión sistémica ocasionada por el VIH podría dar lugar a la reactivación de una infección latente por VPH o al establecimiento de una infección crónica o persistente.

Un grupo de investigadores de Estados Unidos se dedicó a determinar si la infección por VIH y la inmunosupresión facilitan la positividad repetida al VPH y si esto podría explicar la mayor incidencia de NIC en mujeres infectadas por el VIH. En el estudio, que fue longitudinal y duró de 1992 a 1998, se efectuaron exámenes semianuales a 268 
mujeres de Baltimore, Maryland (de las cuales 184 eran positivas a VIH) y se obtuvieron por lavado 1426 especímenes cervicovaginales que fueron sometidos a la prueba de reacción en cadena de la polimerasa. La positividad a VPH y el tiempo transcurrido hasta su desaparición, según la presencia o ausencia de seropositividad al VIH y el recuento de linfocitos $\mathrm{CD} 4+$, fueron comparados mediante la aplicación de modelos para datos binarios correlacionados y análisis de supervivencia. De las 187 participantes que mostraron seropositividad por lo menos una vez, la probabilidad de sufrir positividad a VPH más tarde entre mujeres negativas y positivas a VIH con recuentos de células CD4+ $\geq 200$ y $<200$ células/ $\mu \mathrm{L}$ fue de $47,5,78,7$ y $92,9 \%$ $(P<0,001)$. Los resultados de la prueba detectora de $\mathrm{VPH}$ en una misma mujer se correlacionaron (es decir, se agruparon) en cada categoría $(P<0,01)$. Cuando se compararon con las participantes negativas a VIH, las mujeres positivas a VIH con células CD4+ $\geq 200$ y $<200$ mostraron una incidencia relativa de desaparición del VPH de 0,29 y 0,10, respectivamente $(P<0,001)$. Al final del período de seguimiento, 11 mujeres mostraron una NIC confirmada por biopsia. La asociación entre VIH y NIC $(P=$ $0,014)$ pudo explicarse en su totalidad por la positividad repetida a VPH provocada por la infección por VIH $(P=0,648)$. La regresión de la inmunosupresión después de un tratamiento intenso con agentes antirretrovíricos suele tener una fuerte influencia en la aparición de NIC vinculadas con positividad al VIH. (Ahdieh L, Muñoz A, Vlahov D, Trimble CL, Timpson LA, Shah K. Cervical neoplasia and repeated positivity of human papillomavirus infection in human immunodeficiency virusseropositive and -seronegative women. Am J Epidemiol 2000;151(12):1148-1157.)

\section{Soplan vientos traicioneros}

Mil millones de personas en el mundo, en su mayoría mujeres y niños, sufren exposición a concentraciones cien veces mayores de contaminación ambiental en el interior de edificios que lo recomendado por la OMS, según se informó en una reunión estratégica sobre la calidad del aire y la salud que se celebró en Ginebra, Suiza, en septiembre de 2000. La contaminación del aire, problema de primera magnitud en países desarrollados y en desarrollo, no solo afecta al aire ambiental de las ciudades, sino al que se respira dentro de los edificios y lugares de trabajo. En países en desarrollo, las mayores exposiciones a aire contaminado se producen, precisamente, adentro y obedecen en gran medida al uso de combustibles sólidos para la cocina y la calefacción, como la leña, el carbón de origen mineral, el estiércol, los residuos de materias vegetales y el carbón de origen vegetal. Cuando al uso de estas fuentes de combustión se añade el de estufas que funcionan mal y a la mala ventilación, el resultado es la acumulación de aire contaminado y nocivo dentro del hogar. Esto causa, a su vez, millones de infecciones respiratorias, muchas de las cuales conducen a la muerte, especialmente en niños.

La pureza del aire en el campo es un mito hoy en día. De hecho, casi tres quintas partes de la exposición total a partículas en suspensión, que son la fuente de contaminación ambiental más común en el mundo, tiene lugar en zonas rurales de países en desarrollo. Como suele suceder, las poblaciones de bajos recursos son las más afectadas porque a la mayor exposición a aire contaminado, se suman un mayor riesgo de desnutrición, de enfermedades diarreicas por consumo de aguas contaminadas, y de las consecuencias de una mala infraestructura sanitaria.

En 1990, la OMS calculó que 30\% del número estimado de defunciones causadas por todas las enfermedades se producen antes de los 15 años de edad, pero en el caso de las enfermedades respiratorias agudas, la cifra es el doble. Aunque se conocen los efectos adversos de la contaminación del aire, las medidas preventivas son muy pocas. La reunión celebrada en Ginebra tuvo por objetivo identificar los principales problemas que entraña la creación de una estrategia para combatir los efectos nocivos de la contaminación ambiental. Una dificultad es que, a menudo, los mismos efectos adversos que se pueden atribuir a la contaminación ambiental también son atribuibles a otros factores. Por tal motivo, la OMS considera que es asunto prioritario e indispensable establecer una base de datos sobre los efectos de la contaminación en la salud. Pero antes de que una iniciativa de esta naturaleza pueda surtir los efectos deseados, es preciso idear una metodología uniforme para recolectar datos comparables, en todas partes del mundo, que permitan efectuar evaluaciones acertadas y científicamente válidas de los efectos de la contaminación sobre la salud. (World Health Organization. Danger in the air. Comunicado de prensa $\mathrm{WHO} / 56,14$ de septiembre de 2000.)

\section{Efectos de añadir interleucina-2 a los medicamentos anti-VIH}

Un primer ensayo clínico controlado de carácter aleatorizado sobre el uso de interleucina-2 (IL-2), el primero en realizarse en esta era de tratamientos antirretrovíricos de alta actividad (HAART), reveló que la combinación de un tratamiento inmunológico con antirretrovíricos de alta potencia aumenta muy 
notablemente los recuentos de linfocitos CD4+ sin aumentar la cantidad de VIH en la sangre. Estos resultados, que se dieron a conocer en el número de julio de 2000 de la Journal of the American Medical Association, corroboran los de estudios anteriores según los cuales la terapia con IL-2 a altas dosis puede aumentar los recuentos de células CD4+ en pacientes con infección temprana por VIH. Estos estudios tuvieron lugar, sin embargo, antes de la aparición de la HAART en 1996, de manera que no se sabía si se podía obtener una respuesta terapéutica intensificada al administrar la IL-2 en combinación con un régimen potente a base de antirretrovíricos combinados.

El estudio, que se llevó a cabo de abril de 1996 a abril de 1998 en ocho centros clínicos, evaluó a 78 pacientes positivos a VIH que ya estaban recibiendo tratamiento con antirretrovíricos combinados por indicación de sus médicos particulares. Al inicio del estudio, estos voluntarios tenían muy pocos síntomas o estaban asintomáticos, y tenían recuentos de linfocitos T CD4+ compatibles con enfermedad moderada (200 a 500 células por microlitro). Los voluntarios fueron asignados aleatoriamente a uno de dos grupos: a 37 se les empezó a administrar IL-2 además del tratamiento antirretrovírico, y a los otros 41 se les mantuvo con el tratamiento antirretrovírico exclusivamente. Los que integraron el primer grupo recibieron IL-2 dos veces al día por 5 días (a una dosis inicial de 7,5 millones de unidades internacionales) por inyección subcutánea cada 8 semanas por un total de 6 ciclos durante el año de tratamiento activo. Todos los voluntarios recibieron seguimiento durante un año adicional.

$\mathrm{Al}$ cabo de un año de tratamiento, los recuentos de células CD4+ en el grupo que recibió IL-2 habían aumentado un promedio de $112 \%$, mientras que en el grupo que solamente recibió antirretrovíricos el aumento fue de solamente $18 \%$. También se observó que el primer grupo tenía una carga vírica ligeramente menor que el grupo testigo, y que más voluntarios del primer grupo mostraron una fuerte supresión del virus, con concentraciones víricas inferiores a 50 copias por $\mathrm{mL}$.

Pese a que este estudio es el primero en revelar un efecto favorable de la IL-2 sobre la carga vírica, las diferencias observadas entre los dos grupos no fueron muy grandes y es posible que los efectos beneficiosos de la IL-2 se vean parcialmente eclipsados por el efecto de la HAART. Datos más extensos que permitirán conocer más a fondo los efectos de la IL-2 sobre la carga vírica se darán a conocer públicamente antes de finales de 2000, cuando se publiquen los resultados de dos estudios más extensos de fase 2. (National Institute of Allergy and Infectious Diseases. Adding IL-2 to potent anti-VIH drugs increases CD4+ T-cell counts without raising
HIV levels. Comunicado de prensa de los Institutos Nacionales de Salud, 8 de julio de 2000.)

\section{La hipocolesterolemia y la mortalidad por enfermedades no cardiovasculares}

Según los resultados de ensayos clínicos recientes, las bajas concentraciones de colesterol total en sangre podrían asociarse con un aumento de la mortalidad por causas no cardiovasculares. Diversos estudios aleatorizados han apuntado hacia un aumento de las defunciones por causas no coronarias en personas con bajas concentraciones de colesterol total. Al investigarse las causas de defunción por subcategorías, se ha observado una relación inversa entre el riesgo de accidentes cerebrovasculares y el colesterol total en sangre, y una relación directa entre este último y el riesgo de accidentes cerebrovasculares no hemorrágicos. Algunos cánceres - de pulmón, hígado, tejidos linfáticos y sistema hematopoyético - mostraron una mayor frecuencia en personas con bajas concentraciones séricas de colesterol total. Falta ver si estas asociaciones se observan en personas con hipocolesterolemia natural o en las que tienen bajas concentraciones de colesterol en sangre porque han seguido una dieta o porque han tomado medicamentos que bajan el colesterol. Si de hecho hay una asociación entre bajas concentraciones de colesterol en sangre $\mathrm{y}$ un mayor riesgo de morir de causas no cardiovasculares, aún sigue habiendo mucha incertidumbre en cuanto al mecanismo que explica la asociación.

La inquietud por este tema surgió por primera vez en los años setenta, a raíz de la detección por investigadores japoneses de una asociación ecológica entre las hemorragias cerebrales y las concentraciones de colesterol en la sangre. En 1981 surgieron nuevos datos, obtenidos mediante estudios prospectivos, que apuntaban hacia una relación inversa o en forma de $U$ entre la colesterolemia y el cáncer. En un taller celebrado ese mismo año por la Asociación Estadounidense del Corazón, los Pulmones y la Sangre, se tomó le decisión, sobre la base de los resultados de estudios epidemiológicos prospectivos estadounidenses y de otros países, de no modificar las recomendaciones en vigencia sobre la reducción del colesterol total. Finalmente, en 1990 se dieron a conocer en una conferencia en Bethesda, Maryland, los resultados de un metaanálisis modificado de 19 estudios procedentes de Estados Unidos, Europa, Israel y Japón. Estos resultados son los que respaldan las conclusiones expresadas en los párrafos anteriores.

La mayor parte de las explicaciones de orden biológico que se han dado no han tenido gran 
apoyo, entre ellas la de que las concentraciones bajas de colesterol podrían menoscabar la integridad de la membrana celular. Un argumento contra la presencia de una relación causa-efecto radica en que no se ha detectado una relación cuantitativa entre la colesterolemia y el riesgo de trastornos no cardiovasculares. Además, los estudios no farmacológicos no han revelado un exceso de defunciones de origen no car- díaco. Por consiguiente, aunque está claro que sí existe una relación entre las concentraciones bajas de colesterol en la sangre y el riesgo de morir de causas no cardiovasculares, la mayor parte de los estudios parecen dar lugar a un mayor número de interrogantes que de respuestas. (Meadows AB, Abbott C, Lier K. Low cholesterol and noncardiovascular mortality. Military Med 2000; 165(6):466-469.)

\section{Nueva revista sobre atención al paciente e investigación clínica en poblaciones multirraciales}

Recientemente ha aparecido una nueva revista médica que abordará y buscará soluciones a los retos sanitarios que plantea la creciente diversidad racial de las poblaciones de las Américas, y en particular de los Estados Unidos de América, representada por personas originarias de América Latina, Asia, Pacífico, África y Oriente Medio. Estas poblaciones pueden presentar diferencias genéticas, económicas y culturales, además de diferencias en su susceptibilidad y exposición a agentes tóxicos e infecciosos. La nueva revista, llamada Medicine of the Americas, es una publicación con arbitraje editorial, de periodicidad bimestral. Incluye artículos originales, informes de casos, transcripciones de conferencias, comentarios, reseñas de libros y otros materiales. Entre los temas que se abordarán se encuentran los aspectos sociales y culturales de la prestación de atención sanitaria, las infecciones causadas en los Estados Unidos por microorganismos foráneos, el empleo de tratamientos no farmacológicos o "alternativos" por diferentes grupos étnicos y las presentaciones "poco comunes" en determinadas poblaciones de enfermedades comunes. Aunque inicialmente solo se publicará en inglés, con el tiempo publicará resúmenes y otros materiales en más idiomas. Se puede obtener información sobre suscripciones individuales y colectivas y sobre la presentación de manuscritos dirigiéndose a: Medicine of the Americas, P.0. Box 1930, 17150 Lake Marie Road, Sutter Creek, California 95685, Estados Unidos de América; teléfono (1 209) 2675940; fax: (1 209) 2670845; correo electrónico: info@MedicineoftheAmericas.org

Esta misma información, así como el texto completo de los artículos del primer número de la revista, están disponibles también en Internet en http://www.medicineoftheamericas.org

\section{New Journal on Patient Care and Clinical Research among Multiethnic Populations}

A new medical journal recently debuted that will explore and seek solutions to the health challenges facing the increasingly diverse populations of the Americas, especially in the United States of America, including persons of Latin American, Asian, Pacific Rim, African, and Middle Eastern origins. Such populations may differ genetically, economically, and culturally, as well as in their susceptibility and exposure to infectious and toxic agents. A bimonthly peerreviewed publication, the new journal is entitled Medicine of the Americas. The journal includes articles, case reports, grand rounds, commentaries, book reviews, and other materials. Among the subjects that will be covered are the social and cultural aspects of health care delivery, infections in the United States caused by organisms not native to the country, use of nonpharmaceutical or "alternative" medical remedies by different ethnic groups, and the "uncommon" presentation in certain populations of what are considered common diseases. While initially just in English, the journal may eventually publish abstracts and other materials in additional languages.

Information on individual and institutional subscriptions and on submitting manuscripts is available from: Medicine of the Americas, P.0. Box 1930, 17150 Lake Marie Road, Sutter Creek, California 95685, United States of America; telephone: (209) 267-5940; fax: (209) 2670845; e-mail: info@MedicineoftheAmericas.org

That same information, along with full-text articles from the journal's premiere issue, is provided on the Internet at http://www.medicineoftheamericas.org 